\title{
PROBLEMS OF IDENTIFYING AND REGULATING THE STRUCTURE OF THE LABOUR MARKET IN DEPRESSIVE LITHUANIAN REGIONS
}

\author{
Algis Šileika 1, Daiva Andriušaitienẻ ${ }^{2}$ \\ Vilnius Gediminas Technical University, Sauletekio al. 11, LT-10223 Vilnius, Lithuania \\ E-mail: ${ }^{1}$ algis.sileika@dsti.lt; ${ }^{2}$ daiva.andriusaitiene@dsti.lt \\ Received 26 June 2006, accepted 9 Spalio 2006
}

\begin{abstract}
In order to identify labour market problems in the depressive regions of Lithuania and to provide guiding lines in the search for their solution, it is necessary to conduct a systematic analysis of the structure of employable population encompassing the characteristics of segments of employed and unemployed persons as well as individuals not registered with the official labour market. Correlation and factor analysis of eighteen macroeconomic indicators investigating into indicators of all municipalities of the country and depressive regions separately ( 20 municipalities where the unemployment rate exceeded the average in the country by 1,5 times in 2004) enabled evaluation of the significance of employment and unemployment indicators as well as impact thereof on other indicators chosen for the analysis to feature the trends of social and economic development on national level and in depressive regions in 1996-2004. Apart from special sociological research, characterization of the structure and peculiarities of labour force is confined to assumptions of logical analysis, but the invented technologies give grounds to maintain that dynamics of the employment indicator reflects the trends and outcomes of the development of economic activities only to a certain limited extent. Relation of the unemployment indicator, particularly that of long-term unemployment, with other macroeconomic indicators is much tighter. However, as we can see from the analysis, relevantly big share of employable individuals not participating in the labour market has been little analysed by the structure, though most probably this share consists of the following basic groups: unemployed "volunteers", "labour migrants", unofficially employed individuals and persons employed in in-kind farms. Yet, the analysis of statistical data shows that this is not an idiosyncrasy of depressive regions of the country. In the analysis of the structure of the labour market, the following problems extremely important in the depressive regions of Lithuania may be singled out: long-term unemployment trap determines emigration of youth and better skilled labour force; consequently this results in prevalence of senior and pension-age population, unskilled labour force and out-of-skill individuals in the structure of employable population, and in unofficial, ineffective "survival" employment in small, quasi-in-kind farms that have become a traditional way of life of rural population.
\end{abstract}

Keywords: labour market, employment, unemployment, migration, unregistered employment.

\section{Introduction}

Rapid economic growth in Lithuania gives grounds to expect positive social changes and growing welfare of the national population. It looks like shortage of labour force, which is becoming the major labour market problem on a macro level, should lead to crossing the unemployment problem off the list of the most relevant problems with the exception of one circumstance: there still exist depressive regions, where the unemployment indicator remains quite above the average in the country. Such regions are bypassed by investments, there prevail ineffective agricultural sector, while earnings of the local population are considerably behind average indicators in the country and give grounds to state that poverty and social exclusion are prospering in these regions. In order to identify the labour market problems prevailing in these regions, the first necessary step is a systematic analysis of the structure of labour force, starting from identification of the structure of the first link of the research - employable population, and then identifying portions of unemployed individuals and those not participating in the labour market. The next stage is analysis of the structure of labour force in the depressive regions of the country, including definition of the observed trends and specific features thereof. In this paper we invoke the results of correlation and factor analysis in order to identify the relation of labour market indicators with other macroeconomic indicators.

Identification of determinants of the social economic development in the depressive regions in the country is problematic due to a number of reasons. One of the basic reasons is the lack of indicators characterizing the situation in these regions. Publication Lietuvos Apskritys (Counties of Lithuania), which publishes annual indicators on municipal level, comes up with data only after a year, but even among the published indicators there prevail quantitative ones. For example, there are even 30 agricultural indicators illustrating 
nearly the whole range of agricultural yield in kilos (down to the number of collected eggs) in each municipality, but there are no data about the wage size in the same agricultural or other economic activity. The Lithuanian Statistics publish data about GDP created in counties, but they do not present data about GDP created by separate economic activities, and there are no possibilities to order such data.

One more problem is the continuation of computing statistical indicators. Computation of some indicators is terminated, while others are computed using new methodology and thus they do not suit for an integral data line any longer. Due to the above-mentioned reasons, processes of social economic analysis and solution searching in regions (county level) are considerably more complicated compared to the micro level: lack of data restricts invocation of usual methods of mathematical analysis, direct programming or other methods of functional analysis. Even with sufficient statistical data, a complicated mechanism of factor interface may be fully deformed at different stages of modelling of a social psychological factor (approaches, interests, subjectivity, etc.) and analysis, and task settling.

All the mentioned reasons significantly restrict the selection of the very factors and mathematical statistical methods of computation. All this is also relevant to the analysis of the social economic situation of the depressive regions of the country and, concurrently, the labour market situation of these regions. Accordingly, in order to identify the submerged correlation of processes we often have to simply confine to a local analysis of statistical indicators.

So far, the Lithuanian Statistics has presented the data featuring social economic situation of municipalities for the year 2004 [1]. Published labour market indicators are much more up-to-date, but application thereof in statistical mathematical calculations enabling analysis of in-depth correlation of indicators is restricted by delayed key macroeconomic indicators. Therefore this analysis of labour market structure uses the data of 2004 .

Thus, in order to identify the labour market problems of depressive regions of the country and to find ways to settle them, it is necessary to carry out a systematic and detailed analysis of the labour market structure, encompassing the scale and characteristics of employed and unemployed individuals, and persons not participating in the labour market as well as defining the trends and the most important processes of relevant dynamics.

\section{Employment}

As we can see from the data published by the Lithuanian Statistics (see Fig 1), the number of the employed in the depressive regions of the country is fluctuating from 48 per cent in the municipality of Lazdijai district to 77 per cent in the municipality of Jurbarkas district. Comparing to the average in the country, quite lower employment rates are prevailing in the mentioned municipalities of Lazdijai and Akmenè districts as well as Šalčininkai district. In these regions, employed persons account to as few as a half of the total employable population, while the employment rate in the country exceeded 69 per cent in 2004. Analysis of the structure of the employed in the depressive regions shows that in principle this structure insignificantly differs from the employment situation on national level or in municipalities where registered unemployment is the least. In some municipalities attributable to the depressive regions of the country, e.g., in Jurbarkas district, Kelmè district, Panevéžys district, Pagègiai, the employment rate is even significantly higher compared to the average in the country: $77,75,75$ and 73 per cent respectively. Accordingly, no consistent patterns were revealed by the analysis of the situation in the depressive regions in the light of employment rates only.

In order to identify, in the cross-sectional analysis of the municipalities, the relations of these supposedly scattered employment rates with other 17 indicators featuring social and economic development in municipalities, the authors of this article carried out a correlation analysis. Results of this analysis demonstrated that in the context of all indicators of the Lithuanian municipalities in 1996-2004, the rate of employment is strongly correlated to budgetary expenses of the municipalities $(r=0,166, p<0,01)$, financial investments $(r=0,266, p<0,01)$, scale of works performed by construction companies and enterprises $(r=0,165, p<0,01)$, number of the operating economic entities $(r=0,383, p<0,01)$, municipal expenses for social benefits $(r=-0,240, p<0,01)$, number of retired individuals falling for 1000 employable individuals $(r=-0,300 \mathrm{p}<0,01)$ and unemployment rate $(r=-0,223, p<0,01)$. However, correlation analysis of the same indicators in the depressive regions (20 municipalities) under the same level of significance demonstrated the relation of the employment rate only with the number of the operating economic entities $(r=0,357, p<0,01)$ and the number of secondary and basic school graduates falling for 1000 employable individuals $(\mathrm{r}=-0,356, \mathrm{p}<0,01)$. It should be noted, however, that meaningful strength of the correlation linkage identified in both cases is quite weak. 


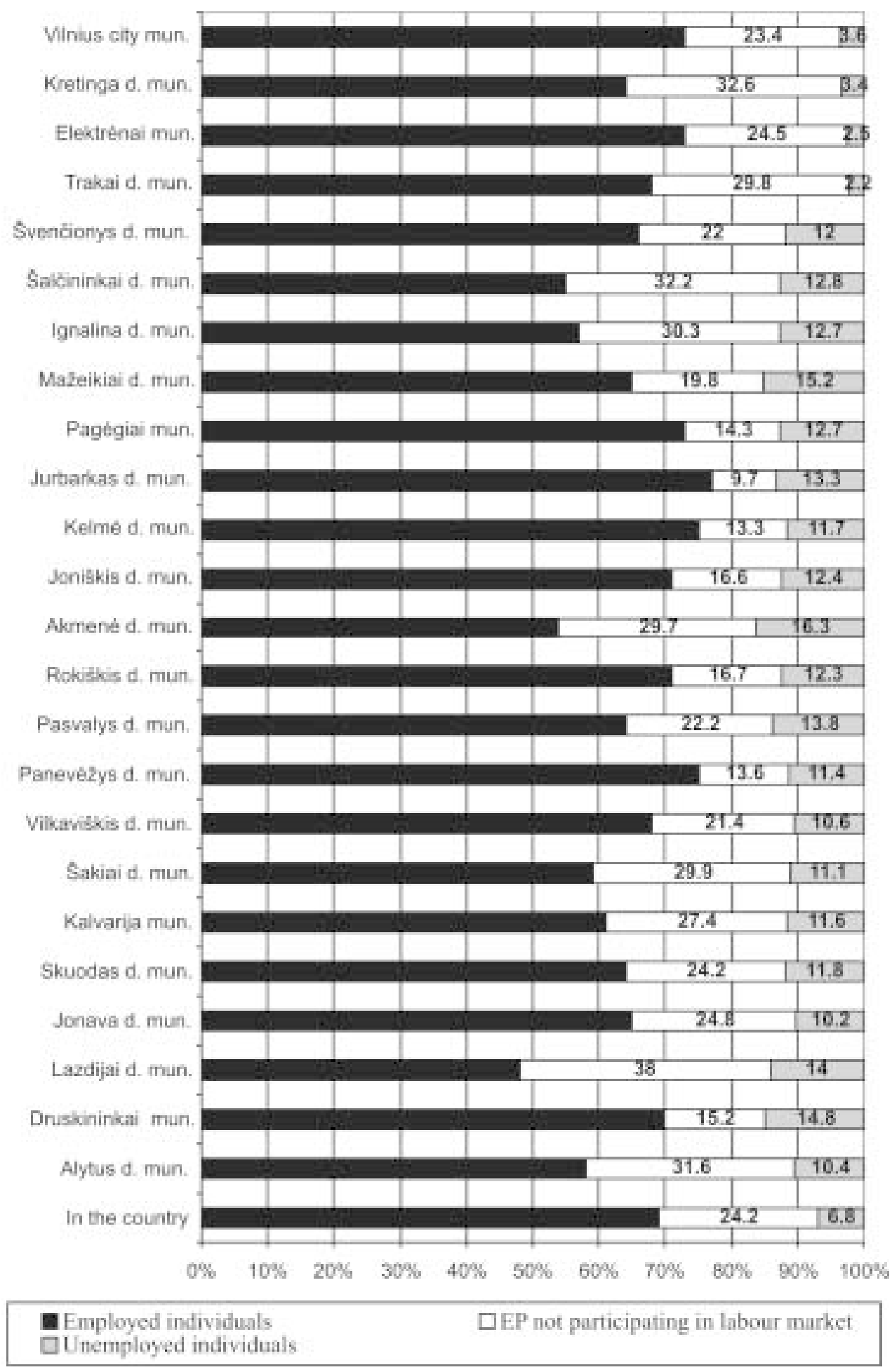

Fig 1. Structure of employable population (EP) in depressive regions of Lithuania in 2004 (\%)

Factor analysis of the same indicators, as carried out on the level of all municipalities of the country, attributed the indicator of employment rates to the group of indicators characterising a demographical situation of the municipality. In addition to the employment rate, this factor encapsulated such indicators as the number of retired individuals falling for 1000 employable in- dividuals, migration balance and portion of the rural population in the total number of the population. The strength of impact of the distinguished group of indicators (factor) on the dynamics of these eighteen indicators equals to 10,2 per cent. Analogue analysis of unemployment rate indicators in the depressive regions only correlated with the indicators of the 
number of retired individuals falling for 1000 employable individuals and the strength of the factor's impact here was measured at 9,3 per cent. Analysis of the indicators of 2001-2004 demonstrated nearly identical results.

Therefore, the results of both correlation and factor analysis show that the indicator of the employment rate features municipalities more in demographic terms, though a mere logical analysis prompts that this indicator should reflect investment and economic activity development trends. This leads to a conclusion that the value of the employment rate indicator and its dynamics do not reflect the trends of economic development in one or another municipality. Identification of factors determining the value and dynamics of the employment rate indicator requires a special sociological research.

\section{Unemployment}

Another link in the labour market structure research is the analysis of unemployment, rate of unemployment and structure of unemployment. The rate of unemployment in the depressive regions was by 2,4 times higher in 2004 compared to the average in the country. The unemployment rate was the highest in the municipalities of Akmene district, Mažeikiai district, Lazdijai district and Druskininkai, i.e., 16,3; 15,2; 14,0 and 14,8 per cent respectively. These rates exceeded the average in the country more than twice and were more than nine times higher compared to the lowest unemployment rates in municipalities of Trakai district and Elektrenai, where this indicator was only 2,2 and 2,5 per cent respectively. The rate of unemployment in the mentioned earlier four municipalities was by five times more compared to the registered average unemployment rate per year in Vilnius in 2004. In the second semester of 2005, when the average unemployment rate dropped down nearly to the natural unemployment margin in the country, municipalities of Akmene and Ignalina districts maintained the highest rates of unemployment, i.e., more than 10 per cent of the employable population in these municipalities were registered with the labour exchange as unemployed. In six other municipalities (Druskininkai and the districts of Lazdijai, Joniškis, Jurbarkas, Mažeikiai and Rokiškis), the rate of unemployment, i.e., the portion of unemployed individuals in the number of employable population, was twice as big as the average in the country.

Results of the correlation analysis demonstrated that on national scale the unemployment rate indicator is correlated to the income of municipal budgets $(r=-0,193, p<0,01)$, budgetary expenses of the municipalities $(\mathrm{r}=-0,185, \mathrm{p}<0,01)$, financial investment $(r=-0,137, p<0,01)$, scale of works performed by construction companies and enterprises $(r=-0,196$, $p<0,01$ ), number of the operating economic entities $(\mathrm{r}=-0,248, \mathrm{p}<0,01)$, municipal expenses for social benefits $(r=0,587, p<0,01)$, rate of employment $(r=-0,223, p<0,01)$, number of secondary and basic school graduates falling for 1000 residents in the municipality $(r=-0,177, p<0,01)$ and longterm unemployment rate $((\mathrm{r}=0,677, \mathrm{p}<0,01)$. Analogue correlation analysis of the same indicators in the depressive regions demonstrated significant relation of the unemployment rate with the income of municipal budgets $(r=-0,466, p<0,01)$, budgetary expenses of the municipalities $(r=-0,404$, $p<0,01)$, number of operating economic entities per capita in the municipality $(\mathrm{r}=0,315, \mathrm{p}<0,01)$, budgetary expenses for social benefits in the municipalities $(\mathrm{r}=0,392, \mathrm{p}<0,01)$, average gross monthly wage $(\mathrm{r}=0,230, \mathrm{p}<0,01)$ and long-term unemployment rate

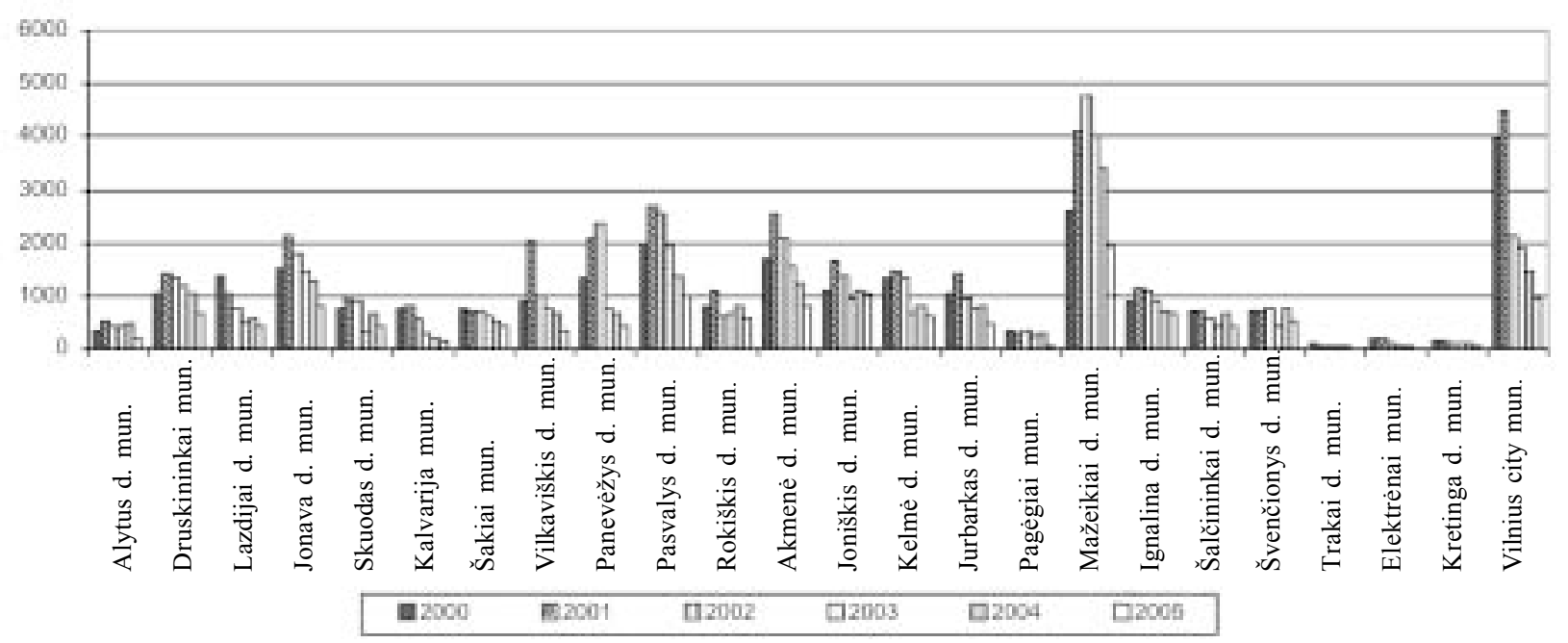

Fìg 2. Number of long-term unemployed individuals in depressive regions of Lithuania in 2000-2005 
$(\mathrm{r}=0,472, \mathrm{p}<0,01)$. Results of the factor analysis (estimating indicators of all municipalities in the country in 1996-2004) showed that unemployment falls within a group of indicators consisting of such indicators as long-term unemployment, municipal expenses for social benefits and sold industrial products per capita in the country. The strength of impact of this factor amounts to 13,4 per cent. According to the analogue analysis of indicators in the depressive regions only, the unemployment rate fell in one factor together with expenses for social benefits from municipal budgets. The strength of impact of this factor makes up 7,6 percent.

In the analysis of the structure of unemployment rate, it would be reasonable to place emphasis on the rates of cyclic, structural and frictional unemployment, but this requires special research. In demographic terms of the structure of unemployment, the structure of the unemployed should be analysed by gender, age, education and place of residents (number of urban and rural population). Research in the specific features of unemployment in depressive regions of the country should stress a predominating characteristic of unemployment in these regions, i.e., long-term un- employment, which scale is highly contrasting to the euphoria invoked by national economic growth. Analysis of the dynamics of long-term unemployment in 2000-2005 (see Fig 2) illustrates that this problem reached its peak in 2001-2002. Later the number of long-term unemployed individuals started dropping down, but in 2005 the number of long-term unemployed individuals in some municipalities (Druskininkai, districts: Jonava, Skuodas, Pasvalys, Akmenè, Mažeikiai and Ignalina) was close to and even higher than in the whole city of Vilnius. In the municipalities of depressive regions, every year more than one quarter of the employable population is unemployed for a period exceeding one year, while some of them are unemployed for five - ten years.

Analysis of 2004 data shows that a portion of longterm unemployed individuals in the municipalities of Pasvalys and Mažeikiai districts (attributed to the depressive regions of the country) was more than by six times higher (57,6 and 58 per cent respectively) compared to the municipalities of Trakai and Kretinga district ( 9,1 and 11,1 per cent respectively), where the rate of registered unemployment was the lowest in 2004 (see Fig 3).

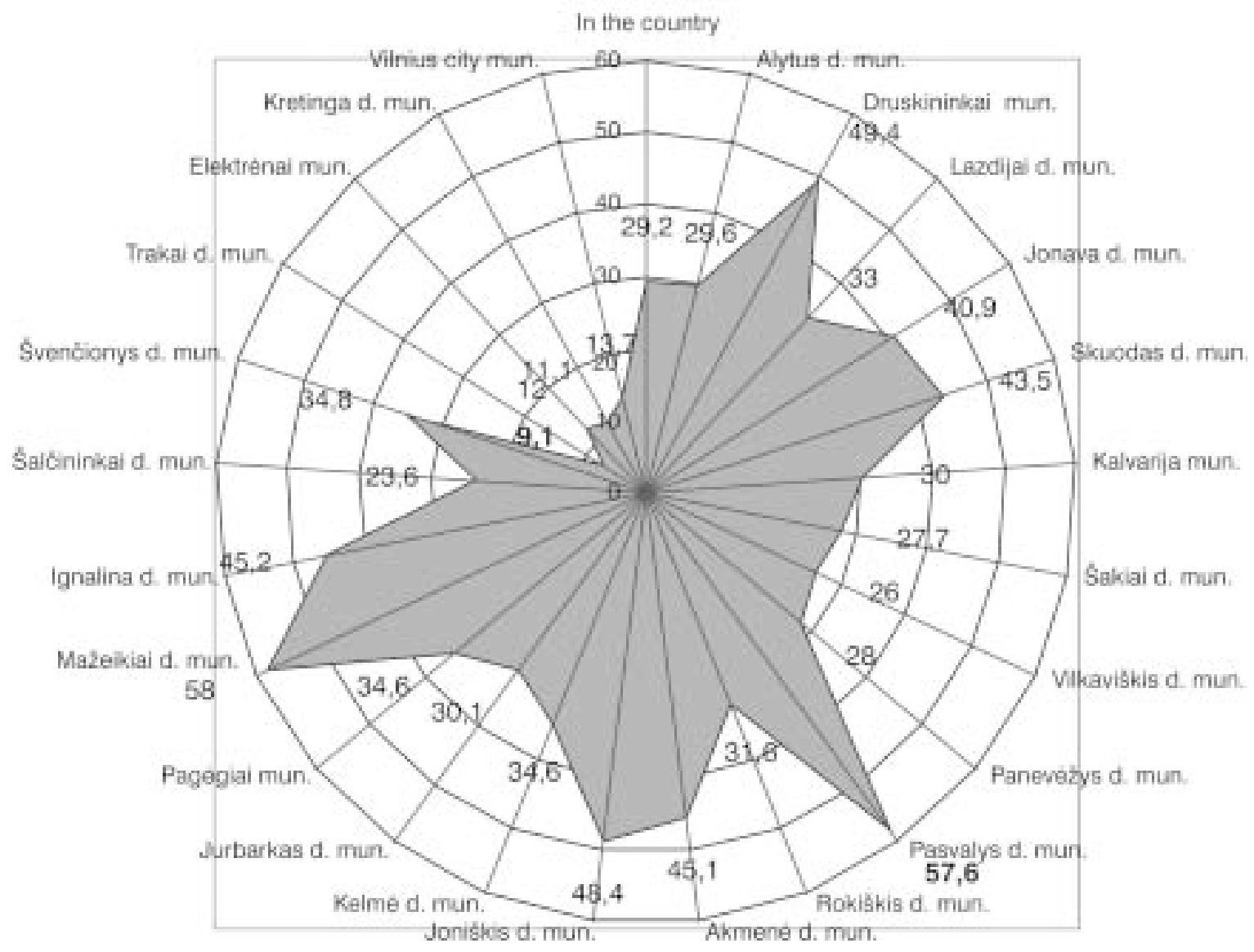

Fig 3. Portion of long-term unemployed individuals in the municipalities of depressive regions of Lithuania in $2004(\%)$ 


\section{Employable population not participating in the labour market}

Unfortunately, the analysis of the structure of the employable population (see Fig 1) shows that apart from employed and registered unemployed individuals, employable population absent from the official labour market both as the employed or as the unemployed accounts for quite a big portion. Their status in the labour market is unclear. Yet, analyses of quantitative values of the indicator in individual municipalities revealed no consistent pattern (see Fig 4). Without special sociological research, it would be absolutely incorrect to speak about the specific structure of this group of individuals omitted in the labour market.

As a matter of fact, this group includes 'volunteer' unemployed individuals; self-employed persons in small unregistered household farms and living on the products created in such farms and casual, one-off jobs; employable population, who migrated from the region to the biggest Lithuanian cities and EU countries; unofficially employed individuals. These are four la- bour market problems prevailing in the depressive regions (and not only there) of the country. These problems could be reviewed as the third link of the research of the labour force structure.

The first of the above-mentioned groups - 'volunteer' unemployed - normally accounts for a few per cent of the total employable population. In most cases these are the persons with social-psychological problems. Their integration in the labour market takes time and is expensive, because this requires complex multidisciplinary decisions $[2,3]$. The second group - persons self-employed in small unregistered farms and living on the products created in such farms and casual, one-off jobs - is to a certain extent a unique Lithuanian product of transition to market economy. It even has its specific national name trihektarininkai (threehectare holders). As we can see from the studies, this group of persons has formed as a pure product of protracted stagnation - depression: after prolonged failures to find their place ir the labour market, these persons found a way to survive in nearly in-kind farms. It is quite a problematic portion of labour force, be-

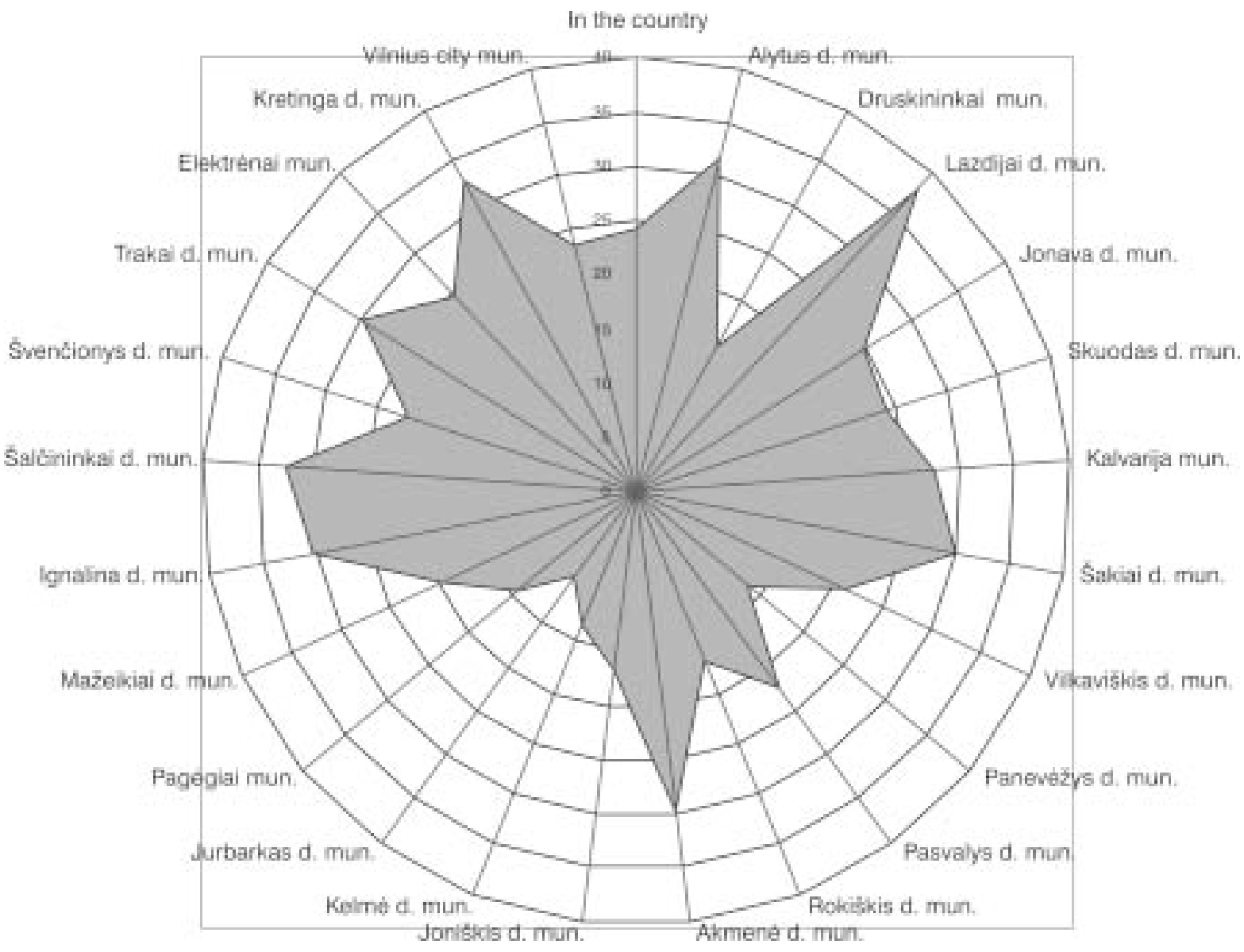

Fig 4. Portion of employable population not participating in the labour market in 2004 
cause in most cases these people have lost their earlier qualifications and hardly respond to integration into the labour market, regardless of active labour market measures, due to poverty and senior age.

The third trend and problem with a negative affect on economic development in the depressive regions of the country is migration process. Analysis of official nationwide data of the Lithuanian Statistics showed that a negative value of the migration balance indicators increased by more than 52 percentage points from 2003 to 2004; recalculation of these indicators per 1000 residents in a municipality, county and country, respectively, gives grounds to conclude that the number of migrants from depressive rural regions (municipalities) of the country exceeds the average in the country (see Fig 5) and often exceeds the average in the county as well. More detailed evaluation of the consistent patterns, scale and consequences of migration structure from the regional aspect requires a special sociological research, but it is quite probable that emigration of employable, relevantly young and better educated individuals has the biggest influence on the growth of the negative migration balance.

Results of the correlation analysis show that the nationwide migration balance indicator is most closely related to the dynamics of such indicators as the number of operating economic entities per capita, the number of retired individuals per 1000 employable population, average monthly gross wage and a portion of rural population in the total number of the population $(r-0,193, r=0,250 ; r=0,181 ; r=0,300$, respectively, where $p<0,01)$. The correlation analysis of analogue indicators in the depressive regions disclosed a significant relation of the migration indicator with direct foreign investments $(\mathrm{r}=-0,330$, where $\mathrm{p}<0,01)$, portion of rural population $(r=0,365$, where $p<0,01)$. What is of particular interest, is correlation of migration with income of municipal budgets per capita $(r=-0,281$, where $p<0,05)$, but even stronger correlation is defined with the indicator of expenses of municipal budgets per capita $(r=-0,298$, where $p<0,01)$. It is obvious that emigration of regional population results in the loss of potential income of the municipalities, but at the same time this reduces a portion of budgetary expenses spent by the municipalities per capita. The ironic truth is the fewer people, the fewer problems. When there is no labour force, investments are also senseless. Estimates show that people who stay in such regions are retired individuals resolved "to live up to the end of their days" and rural population where majority of them simply try "to survive" without any bigger ambition for better personal welfare. Depressive regions of the country become more and more abandoned unpromising territories in Lithuania.

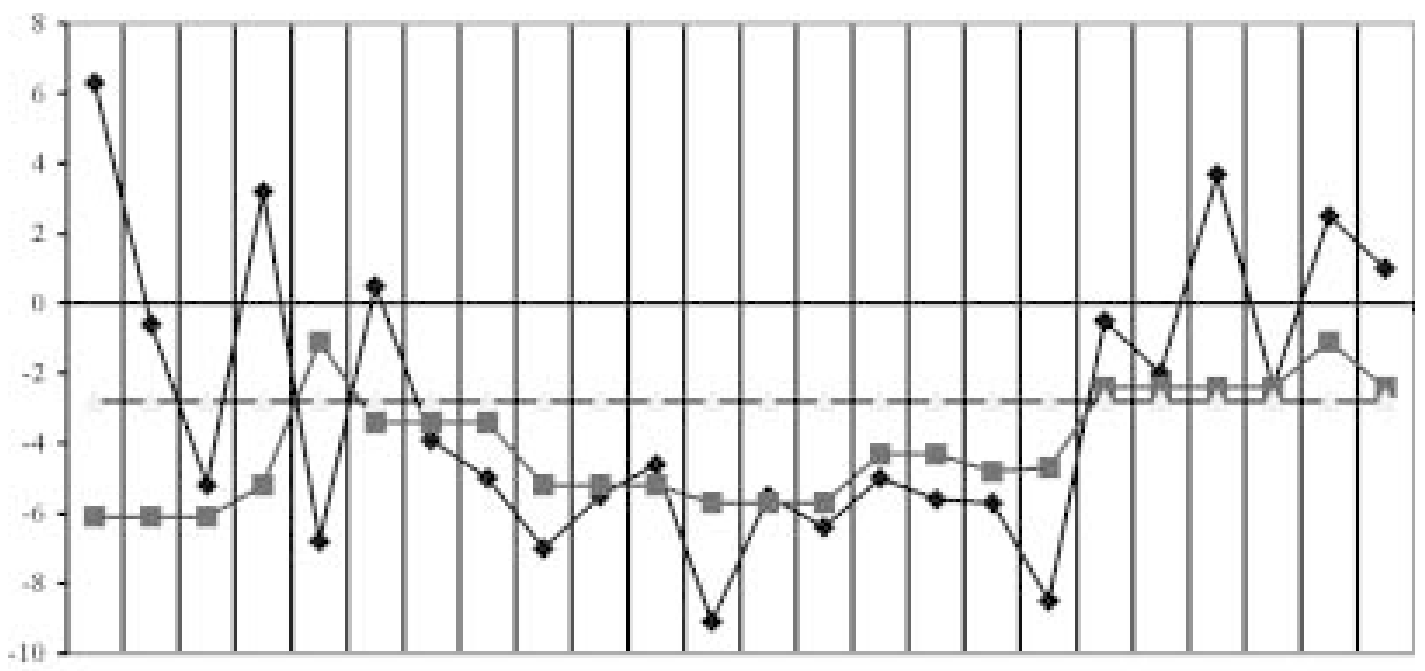

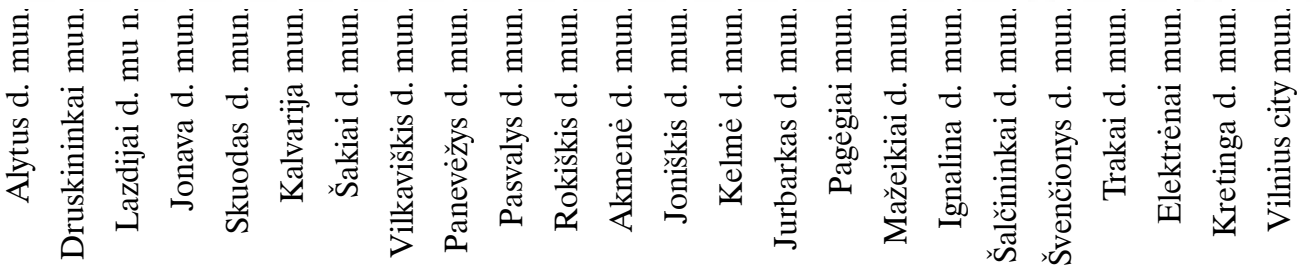

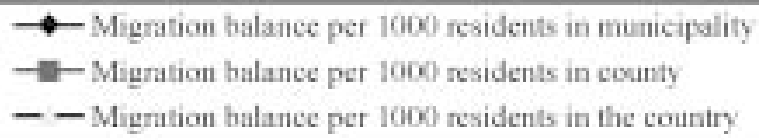

Fig 5. Migration balance in municipalities of the depressive regions of the country in 2004 
In Lithuania there have been no special studies so far, enabling consistent analysis of trends, causes and consequences of the migration of labour force in the depressive regions. Yet, consistent patterns and peculiarities discovered by foreign scientists as characteristic for migration processes in depressive regions $[4,5]$ as well as data of research in the labour market carried out in Lithuania lead to a conclusion that territories with the highest unemployment rates are abandoned by young, better skilled individuals. Thus, these regions lose the most promising share of labour force. As a flow, higher skills go to better developed regions and get concentrated there. To somewhat lower extent, labour force in the depressive regions is supplemented with poorer skilled labour force. These processes of domestic migration increase concentration of human capital in regions featuring higher pace of development. Consequently, potential of future development is increased in the latter regions, while development opportunities of the depressive regions are considerably reduced both in quantitative (the number of employable population is dropping down) and qualitative (level of skills of labour force is getting lower) terms. The basic reason of this process is unemployment. Low qualifications determining few opportunities in the labour markets of other regions, land owning ensuring cheap subsistence, and low market value of such ownership are the basic reasons of domestic migration flows. Accordingly, even low migration level itself becomes a precondition for non-decreasing unemployment, particularly, long-term unemployment. This is one more proof that long-term unemployed individuals from depressive regions of the country are stuck in unemployment trap.

One more group of employable population falling within the group of persons not participating in the labour market are persons employed in unofficial labour market. As we can see from scientific researches [6], unofficial employment has nearly doubled over two decades (from 1978 to 1998). In 2002, the informal sector made up for approx. 10 per cent GDP in Nordic countries, the United Kingdom and Switzerland, from 20 to 30 per cent in South Europe and Ireland. According to experts, there could be about 180-200 thousand of unofficial employed individuals in Lithuania. Precise data could be obtained only if a special research is made. Anyhow, it is highly probable that a big portion of individuals absent from the official labour market in the depressive regions of the country are represented by unskilled or very low-skilled individuals surviving on casual short-term jobs with small farmers and providing their services on the basis of "bees" in other in-kind farms. Somewhat bigger portion of unofficially employed individuals is expected in construction and car resale business.

When trying to answer the question why the informal sector is tolerated, one of assumptions made by scientists is a probability of rapid growth of unemployment in case of repressions against unofficial employment. Another argument tells that, at any rate, unofficial employment creates a higher added value than unemployment does. Researchers of unofficial employment stress a close interrelation of limits and interfaces between two phenomena - unofficial employment and official unemployment as well as consistent patterns of their dynamics defining this as an economic phenomenon: they are as if two necessary economic forces, or the two sides of a medal. It is also emphasised that any economic or political measure, which reduces one of them, facilitates the increase of the other one [6].

Companies falling under shadow economies may be classified into two types: companies operating in lowefficiency sectors with prevailing inefficient jobs and companies operating in quite efficient sectors with prevailing highly efficient jobs. The latter type of companies or jobs falling under unofficial employment (or some part of them) is peculiar for the reason of having more opportunities or disposition to legalise, i.e., to shift to official employment. Companies operating in the sectors of poor efficiency (agriculture in particular) or jobs in such companies have significantly fewer opportunities to legalise: prevailing inefficient labour determines very low profitability of such companies and this, in its turn, prevents internal and external investments. Consequently, without investments and opportunities to improve technologies such jobs and potential of such companies to grow and legalise are very poor. This is the situation prevailing in the depressive Lithuanian regions.

Unofficial employment as if finds a balance between official unemployment and employment. Theoretically, the indicator of unofficial employment may be an indicator characterising the impact of tax burden on the structure of the labour market. The balance sets in that point where official employment is affordable, i.e., along a line where tax burden and the level of governmental regulation are bearable by employers (small business in particular). If we look at the structure of the labour market from this angle (as at a simplified model of the labour market consisting of $3 \mathrm{seg}$ ments: official employment, registered unemployment and unofficial employment), we can be more precise in selection of labour market regulation measures aimed at working on unofficial employment without increasing 
the rates of official unemployment. Measures reducing tax burden (Fig 6, pointer "A") give grounds to expect increase of official employment as a result of legalisation of companies. If the government decides to enforce stricter (repressive) measures against unofficial employment (Fig 6, pointer "B"), unofficial employment drops down concurrently increasing the rate of registered unemployment.

The aforesaid is important for several reasons. The most important of them are related to doubts as to whether combating unofficial employment is really effective in economical terms, taking into account and considering an impact unofficial employment has on the creation of jobs, cancellation of jobs, maintaining qualifications of employees, living standards of unofficially employed persons and their families compared to the impact of official registered unemployment on the same labour force characteristics. Worldwide experience shows that any labour market regulation policy measure influences not only the unemployment rates, but the rates of unofficial employment as well, i.e., it is very difficult to reduce unofficial employment without facilitating the increase in unemployment rates. Before applying one or another measures, repressive ones in particular, likely to reduce unofficial employment, it is necessary to judge whether there is a supply of official job opportunities, whether tax burden is reasonable in the context of the purchasing power of the population of a particular country or a region. These issues should be tackled eliminat- ing ultimate options, because going over the top to one or another direction may inspire economic and social problems.

As we can see from researches of Italian scientists, in Italy, a portion of unofficial employment varies from 10 per cent in Northwest regions to 30 per cent in South (Sicily). A similar situation has been observed for more than ten years. Strict measures against unofficial employment are usually self-defeating. Making or applying more severe penalties inspires a rapid jump in unemployment rates [6]. Application of such measures results in decreasing pace of creation of job opportunities and cancellation of the least efficient jobs (failure) in the segment of shadow business as well as growth of registered unemployment as a result thereof. This is the basic and most probably the only reason why OECD countries "tolerate" the informal sector. The only effective way of minimising unofficial employment is the development of legal labour market (including measures increasing the mobility of labour force) and, simultaneously, reduction of unemployment by means of looking for the ways enabling more active accommodation of labour market and economic needs, creating maximum opportunities for the employed to move from shadow labour market into the legal one. As we can see from researches, in structural terms, unofficial employment consists of low-efficient jobs. Development of unofficial employment also covers a small part of registered unemployed individuals. One of extremely ef-



Fig 6. Impact of tax burden and governmental administrative regulation levers on the structure of labour market 
fective measures preventing unofficial employment from anchoring is improvement of the system of passive labour market policy measures (unemployment benefits, unemployment insurance), aiming at such a mechanism under which benefits of unemployment insurance should be paid only to those unemployed individuals who may prove their work experience of the official labour market, i.e., have work experience from earlier periods.

\section{Conclusive findings}

1. In order to identify the labour market problems prevailing in depressive regions and top find ways to settle them, the first step to take is a systematic and detailed analysis of the structure of labour market in these regions enabling precise evaluation of the scale and characteristics of employed and unemployed individuals, persons not participating in the labour market as well as trends of dynamics and key processes thereof. However, this task is problematic due to a number of reasons: lack of and delayed indicators characterising the situation in municipalities as well as changes in the very methods of such indicators. Analyses have to base on quite out-of-date data. This also restricts the selection of likely mathematical statistical calculation methods.

2. Correlation and factor analysis of eighteen macroeconomic indicators, featuring economic, social and demographic situation in the municipalities of the country and depressive regions separately, show that the employment rate characterises the municipalities more in demographic terms, though a mere logical analysis prompts that this indicator should reflect investment and economic activity development trends. This leads to a conclusion that the value of the employment rate indicator and its dynamics only partially reflect the situation in one or another municipality. Identification of factors determining the value and dynamics of this indicator requires a special sociological research.

3. Results of the correlation analysis demonstrated that on nationwide scale the unemployment rate indicator is correlated to budget income of municipalities, budgetary expenses of the municipalities, financial investments, scale of works performed by construction companies and enterprises, number of the operating economic entities, municipal expenses for social benefits, number of university or college graduates falling for 1000 residents in a municipality and unemployment rate. However, correlation analysis of the same indicators in the depressive regions demonstrated the strong relation of the unemployment rate with most social-economic and demographic indicators of municipalities. Results of the factor analysis demonstrated that in the context of indicators of all Lithuanian municipalities in 1996-2004 unemployment falls within a group of indicators consisting of such indicators as longterm unemployment, municipal expenses for social benefits and sold industrial products per capita. Quantitative values of the established correlation leads to a conclusion that the unemployment rate indicator is, more than employment, featuring not only social situation of the municipalities, but the economic situation as well.

4. The analysis of the structure of the employable population shows that apart from employed and registered unemployed individuals, employable population absent from the official labour market accounts for quite a big portion. Their status in the labour market is unclear. This group includes 'volunteer' unemployed individuals, selfemployed persons in small unregistered household farms and living on the products created in such farms and casual, one-off jobs, 'labour migrants' - employable population, who migrated from the region to the biggest Lithuanian cities and EU countries, and unofficially employed individuals. Specific features of employable population not participating in the labour market are as follows: their structure is difficult to define though, no doubt, it is non-homogeneous and covers quite a big portion of the employable individuals.

5. The size of migration processes is insufficiently clear, but the trends are predictable. However, even quite obsolete official migration data and their interface with other macroeconomic indicators are enough to state that population emigration from depressive regions results in the loss of potential income of the municipalities, but at the same time this reduces a portion of budgetary expenses spent by the municipalities per capita. The ironic truth is the fewer people, the fewer problems. When there is no labour force, investments are also senseless. Estimates prove that territories with the highest unemployment rates are abandoned by young, better skilled individuals. Thus, these regions lose the most promising share of labour force. As a flow, higher skills go to better developed regions, while people who stay in depressive regions are retired individuals resolved "to live up to the end of their days" and rural population where majority of them sim- 
ply try "to survive" without any bigger ambition for better personal welfare. Depressive regions of the country become more and more abandoned unpromising territories in Lithuania.

6. There are no reliable data about individuals employed in unofficial labour market, but it is quite probable that a big portion of individuals absent from the official labour market in the depressive regions of the country are represented by unskilled or very low-skilled individuals surviving on casual short-term jobs with small farmers and providing their services on the basis of "bees" in other in-kind farms. Somewhat bigger portion of unofficially employed individuals is expected in construction and car resale business.

7. Unofficial employment as if finds a balance between official unemployment and employment. Theoretically, the indicator of unofficial employment may be an indicator characterising the impact of tax burden on the structure of the labour market. The balance sets in that point where official employment is "affordable", i.e., it goes along a line where tax burden and the level of governmental regulation are bearable by employers (small business in particular). When looking for effective levers regulating the structure of the labour market, we should not forget that measures reducing tax burden give grounds to expect increase of official employment as a result of legalization of companies. If the government decides to enforce stricter (repressive) measures against unofficial employment, unofficial employment drops down concurrently increasing the rate of registered unemployment.

\section{References}

1. Counties of Lithuania 2004. Lithuanian Statistics at the Government of the Republic of Lithuania, 2004. 502 p.

2. Экономика труда и социально-трудовые отношения / Под ред. Г. Г. Меликьяна, Р. П. Колосовой. Moscow: MGU, 1996. 623 p. (in Russian).

3. Bornhorst F.; Commander, S. Regional unemployment and its persistence in transition countries. Institute for the study of labour. Discussion paper No 1074. March 2004. 22 p.

4. Boeri, T.; Garibaldi, P. Shadow activity and unemployment in a depressed labour market. Shneider and Enste. Shadow Economies: Size, Causes, and Consequences, Journal of economic literature, 58(1), 2000, p. 77-114.

5. Misiūnas, A., Svetikas, Ž. Evaluation of economic disparities in Lithuanian regions. Ekonomika, 2003, No 64, p. 84-91 (in Lithuanian).

6. Bedard, M. The economic and social costs of unemployment. Applied research branch Strategic policy human resources development Canada, 1996. 25 p. 